\section{Improving the time resolution of surfzone bathymetry using in situ altimeters} \\ Melissa Moulton $^{1 *}$, Steve Elgar $^{1}$, and Britt Raubenheimer ${ }^{1}$ \\ ${ }^{1}$ Woods Hole Oceanographic Institution, Woods Hole, MA, USA. \\ *Corresponding author: mmoulton@whoi.edu, 215-913-2578 (phone), 508-457-2194 (fax)
}

\begin{abstract}
Surfzone bathymetry often is resolved poorly in time because watercraft surveys cannot be performed when waves are large, and remote sensing techniques have limited vertical accuracy. However, accurate high-frequency bathymetric information at fixed locations can be obtained from altimeters that sample nearly continuously, even during storms. A method is developed to generate temporally and spatially dense maps of evolving surfzone bathymetry by updating infrequent spatially dense watercraft surveys with the bathymetric change measured by a spatially sparse array of nearly continuously sampling altimeters. The update method is applied to observations of the evolution of shore-perpendicular rip current channels (dredged in Duck, NC, 2012) and shore-parallel sandbars (observed in Duck, NC, 1994). The updated maps are compared with maps made by temporally interpolating the watercraft surveys, and with maps made by spatially interpolating the altimeter measurements at any given time. Updated maps of the surfzone rip channels and sandbars are more accurate than maps obtained by using either only watercraft surveys or only the altimeter measurements. Hourly altimeter-updated bathymetric estimates of five rip channels show rapid migration and infill events not resolved by watercraft surveys alone. For a two-month observational record of sandbars, altimeter-updated maps every 6 hours between nearly daily surveys improve the time resolution of rapid barmigration events.
\end{abstract}

Key words: Altimeters; Bathymetric surveys; Rip channels; Rip currents; Sandbars; Surf zone 


\section{Introduction}

Surfzone bathymetry controls wave shoaling, refraction, and breaking, and consequently affects wave-driven setup, nearshore currents, and the transport of nutrients, biota, and sediment. On energetic sandy coastlines, the seafloor can evolve dramatically within several hours. Cusps and channels associated with rip currents (Chen et al. 1999; Haller et al. 2002; MacMahan et al. 2006; Austin et al. 2010; Dalrymple et al. 2011; and many others) migrate and flatten quickly in the presence of wave-driven alongshore flows (Falqués et al. 2000; van Enckevort and Ruessink 2003; Garnier et al. 2013), and sandbars migrate rapidly offshore during storms (Thornton et al. 1996; Gallagher et al. 1998a; Hsu et al. 2006; and many others). Nearshore hydrodynamic model results are sensitive to bathymetry (Plant et al. 2002; Plant et al. 2009), and often the largest model errors are associated with poor temporal resolution of bathymetric changes (Wilson et al. 2010). Obtaining surfzone bathymetry with sufficient spatial and temporal sampling for developing, testing, and improving models, especially during energetic conditions, is challenging.

Watercraft with surveying equipment are used to map the surfzone seafloor with high spatial resolution (Birkemeier and Mason 1984; MacMahan 2001; Dugan et al. 2001; Lippmann and Smith 2008), but these techniques usually are restricted to calm conditions preceding and following storms, and thus the temporal evolution of the largest bathymetric changes is not resolved well. During times when waves and bubbles prevent watercraft surveys, observations of evolving bathymetry may be obtained by remote sensing techniques (Holman and Haller 2013). By taking advantage of the depth-dependence of wave speed and dissipation (van Dongeren et al. 2008; Holman et al. 2013) and by assimilating in situ observations (Wilson et al. 2010; Birrien et al. 2013), video observations may be used to estimate bathymetry at low cost and with reasonable vertical accuracy (roughly $0.5 \mathrm{~m}$, Holman and Haller 2013), which has allowed for long-term monitoring of changes in the position of nearshore sand bars and rip current channels (Lippmann and Holman 1989; Holman et al. 1993; Holland et al. 1997; Ruessink et al. 2000; van Enckevort et al. 2004; Holman et al. 2006; Gallop et al. 2011; and many others). However, remotely sensed bathymetric inversion techniques usually are limited to timescales of several days or longer and to spatial scales of $10 \mathrm{~m}$ or greater (van Dongeren et al. 2008; Holman et al. 2013), and for some studies video observations may not be available or may not provide 
sufficient vertical accuracy.

In contrast, in situ altimeters provide accurate, nearly continuous estimates of the distance between the sensor and the seafloor (Gallagher et al. 1996; Gallagher et al. 1998a; Gallagher et al. 1998b). Usually, altimeters are deployed at a limited number of locations, and thus may not resolve the spatial structure of the seafloor evolution, while watercraft surveys offer good spatial resolution, but at a limited number of times. Combining the two data sets should produce higher temporal resolution maps of the seafloor than obtained with infrequent spatially dense watercraft surveys, and higher spatial resolution maps than obtained with spatially sparse altimeters. Data with irregular sampling and errors may be combined with interpolation and mapping techniques (Ooyama 1987; Plant et al. 2002) and data assimilation methods (van Dongeren et al. 2008; Holman et al. 2013; Wilson et al. 2010; Birrien et al. 2013). Here, a method is presented that seeks an accurate estimate of a spatially smoothed bathymetry by updating spatially dense watercraft surveys with temporally continuous, spatially sparse altimeter estimates of seafloor elevation change. The method is tested for two datasets that span a wide range of variability in the surf zone, including observations of migrating and filling shore-perpendicular rip channels dredged on a sandy ocean beach near Duck, NC in 2012, and observations of a migrating shoreparallel sandbar near Duck, NC in 1994. The methods used for measuring (Section 2) and mapping (Section 3) surfzone bathymetry are described, and are tested and applied for the rip channel (Section 4) and sandbar (Section 5) datasets, and the results are discussed and summarized (Section 6).

\section{Direct estimation of seafloor location}

\subsection{Vehicle surveys}

Small personal watercraft can navigate effectively in shallow water under moderate waves, and when equipped with GPS and bottom-finding sonar can be used to map surfzone bathymetry (MacMahan 2001; Dugan et al. 2001; Lippmann and Smith 2008). A jetski (waverunner) was used in the 2012 Duck, NC experiment discussed in Section 4. Typically, watercraft surveys are performed along cross- and alongshore tracks, with spacing between tracks and sample density 
along tracks dependent on the experimental design and survey system. The horizontal accuracy of differential GPS systems is about 0.25 to $0.50 \mathrm{~m}$. The vertical accuracy from individual bedlevel estimates from acoustic pings is about 0.05 to $0.10 \mathrm{~m}$ (this includes $0.02-0.04 \mathrm{~m}$ errors in GPS vertical estimates, and 0.03-0.06 m errors in the estimate of the distance from the transducer to the bed, but does not include the effects of short-horizontal-scale features such as wave-orbital ripples and megaripples). Watercraft provide estimates of the seafloor location over a wide area in a relatively short time, but often are less effective in the surf zone because the approximately $10 \mathrm{~km} / \mathrm{hr}$ speed precludes averaging (at any one location) of many acoustic returns, some of which can be obscured by breaking-wave induced bubbles.

In contrast with acoustic systems that are degraded by bubbles, amphibious vehicles can be used to map the seafloor even in an active surf zone. For the 1994 Duck, NC experiment described in Section 5, the CRAB, a tall three-wheeled vehicle that is tracked with a laser survey system (Birkemeier and Mason 1984) was used to map the seafloor. The CRAB operates from above the high-tide line to 8 -m water depth in waves up to $2 \mathrm{~m}$ high, travels at up to $4 \mathrm{~km} / \mathrm{hr}$, has vertical accuracy of 0.03 to $0.10 \mathrm{~m}$, and has a horizontal resolution of roughly $8 \mathrm{~m}$ (the spacing between the wheels) (Birkemeier and Mason 1984).

\subsection{Fixed Altimeters}

Fixed acoustic devices (altimeters) also may be used to find the seafloor (Gallagher et al. 1996). Altimeters can be deployed during calm conditions, and continue to sample during large wave events when watercraft cannot operate. Moreover, by sampling relatively rapidly at one location, the acoustic returns from a fixed altimeter can be used to find the seafloor even if bubbles obscure the signal most of the time or if the transducer is coming in and out of the water in wave troughs at low tide. Altimeters have been used to investigate sandbar evolution (Gallagher et al. 1998a; Elgar et al. 2001; Hoefel and Elgar 2003; Henderson et al. 2004; Hsu et al. 2006; and many others), bottom roughness (Feddersen et al. 2003; Gallagher et al. 2005), and bedforms (Gallagher et al. 1998b). Although fixed altimeters can find the seafloor in the surf zone, it is difficult to deploy and maintain more than a few dozen instruments (resulting in limited spatial resolution) for more than a few months. Altimeter estimates of the seafloor location can be biased owing to survey errors in the vertical elevation of the acoustic transducers (0.04- $0.10 \mathrm{~m})$. 
In addition, there are randomly distributed errors owing to the finite bin size of the acoustic returns and to the algorithm used to detect the bottom in a time series of noisy acoustic returns.

In the 2012 Duck, NC experiment, single-beam acoustic altimeters recently developed at the Woods Hole Oceanographic Institution (WHOI altimeter, $1 \mathrm{MHz}$ beam, $2 \mathrm{~Hz}$ echo amplitude averaged to $1 \mathrm{~min}, 0.01 \mathrm{~m}$ vertical bins) were used to monitor changes in the surfzone seafloor. During a performance test, a WHOI altimeter deployed on a pipe in the surf zone found the distance from the transducer to the bed (Fig. 1) with roughly $0.05 \mathrm{~m}$ accuracy even in the presence of bubbles in a saturated surf zone (offshore significant wave height of $2.5 \mathrm{~m}$, surfzone wave height of $1.5 \mathrm{~m}$ ). Older versions of the altimeters (used in the 1994 Duck, NC experiment) performed well during large storms with offshore wave heights greater than $4.0 \mathrm{~m}$ (Gallagher et al. 1996; Gallagher et al. 1998a).

The backscatter strength from acoustic Doppler current profilers (ADCP) also may be used to find the seafloor. For example, a Nortek Aquadopp (three $2 \mathrm{MHz}$ beams, one-minute-average echo amplitude in $0.10 \mathrm{~m}$ bins averaged over the three beams) sampling in a saturated surf zone (during the 2012, Duck NC experiment) usually found the bottom within one bin (Moulton et al. 2013), although the bottom signal was weaker and less robust to bubbles than the signal from the faster-sampling WHOI Altimeter.

\section{Bathymetric mapping methods}

\subsection{Spatially dense watercraft surveys}

The time to complete a watercraft survey is short relative to the timescale of morphological evolution, and thus the bed-level estimates are treated as a snapshot of the bathymetry at time $t_{S}$, where $t_{S}$ is the time of the middle of the survey. At each survey time $t_{S}$, there is a spatially dense and irregularly sampled set of bed-level observations. The observations can be interpolated to form an estimate of the bathymetry $Z_{S}\left(x, y, t_{S}\right)$ at a set of regularly spaced spatial coordinates $(x, y)$. If multiple surveys are available, the time evolution of the bathymetry could be estimated by interpolating in both space and time to form at estimate of the bathymetry $Z_{S}(x, y, t)$ at a set 
of times $t$. Properties (e.g., smoothness, agreement with observations) of the mapped bathymetry $Z_{S}$ may be controlled by the choice of interpolation weights in space and time (see Appendix).

For the watercraft survey data presented here, spatial interpolation weights are chosen with a scale-controlled objective mapping method (Ooyama 1987, Plant et al. 1999) to account for unresolved features such as ripples and megaripples. The interpolation weights are found assuming a Gaussian covariance function with scales $L_{x}$ (in the cross-shore) and $L_{y}$ (in the alongshore), a spatially and temporally uniform variance $V_{S}$ (the average variance estimated from all observations), and an observation error $\epsilon_{O}$. The observation error $\epsilon_{O}$ includes the measurement error in the bed level estimated by each acoustic return, plus the root-mean-square (rms) amplitude of features with length scales less than $L_{x}$ and $L_{y}$ (see Appendix). For dense sampling (many observations within a radius $L_{x}$ or $L_{y}$ ), computation time may be reduced by binning the observations prior to mapping, where the error for each binned value is estimated assuming each bottom return is an independent bathymetric estimate. A mean beach slope (computed from all observations) is removed from the observations before mapping, and added back after mapping, such that the estimate approaches the mean profile far from observations (see Appendix). The resulting maps are a smooth estimate of the bathymetry resolving scales greater than or equal to $L_{x}$ and $L_{y}$. A map of the estimated errors $\epsilon_{S}\left(x, y, t_{S}\right)$ is computed for each watercraft survey map (see Appendix). The bathymetry at an arbitrary time $Z_{S}(x, y, t)$ can be estimated by linearly interpolating (inverse separation weighting, see Appendix) between two surveys.

\subsection{Temporally dense altimeter bed levels}

Altimeters sample nearly continuously, providing temporally dense estimates of the seafloor location. At each altimeter location $\left(x_{A}, y_{A}\right)$, where $x_{A}$ and $y_{A}$ are the cross- and alongshore coordinates of the altimeter, there is an estimate of the bed level at a set of times. Interpolation is used to compute an estimate of the bathymetry $Z_{A}(x, y, t)$ on a regular grid $(x, y)$ at a set of times $t$, and properties of the bathymetric estimate are controlled by the choice of the interpolation weights, which are found with a scale-controlled objective mapping method. To reduce computation time, the spatiotemporal interpolation is separated into two steps by assuming space-time separability of the covariance (effectively ignoring small and poorly 
constrained space-time interactions in the covariance between the widely separated altimeters) (Genton 2007). First, the altimeter bed levels are interpolated in time to yield $Z_{T}\left(x_{A}, y_{A}, t\right)$. The interpolation is performed assuming a Gaussian temporal covariance with timescale $T$, a spatially and temporally uniform variance $V_{T}$ (the average variance estimated from all observations, equal to $V_{S}$ ), and measurement rms error $\epsilon_{r m s}$ (the error in the estimate of the distance from the transducer to the bed plus the rms amplitude of unresolved scales). A linear trend is removed from the time series prior to interpolating, and added back after interpolating. If the timescale $T$ is chosen to be larger than the time between bed-level estimates and larger than the period of migrating bedforms, the temporal interpolation step leads to smoothed time series with rms error $\epsilon_{T}\left(x_{A}, y_{A}, t\right)<\epsilon_{r m s}$ owing to averaging over random measurement errors and migrating ripples. A bias error $\epsilon_{\text {bias }}$ (associated with measurements of the vertical elevation of the transducer) is added to the error estimate for the interpolated time series. Next, at each time, the timeinterpolated bed-level estimates are interpolated in space assuming a Gaussian spatial covariance with scales $L_{x}$ and $L_{y}$, a spatially and temporally uniform variance $V_{A}$ (equal to $V_{S}$ ), and a measurement error $\epsilon_{T}\left(x_{A}, y_{A}, t\right)+\epsilon_{\text {bias }}$. A mean beach slope (computed from all observations) is removed from the observations before interpolation, and added back after interpolation, such that the estimate approaches the mean profile far from observations (see Appendix). Ideally, altimeter arrays are designed such that sensors are spaced more densely than one half of the decorrelation scale of the features of interest, but logistical difficulties often lead to undersampling, and thus there are regions far from altimeters where insufficient bathymetric information is available (and interpolation weights approach zero). The spatial interpolation yields a set of maps $Z_{A}(x, y, t)$ and an error estimate $\epsilon_{A}(x, y, t)$.

\subsection{Update method for combining all observations}

At the times of surveys, it is expected that the spatially interpolated watercraft surveys are the best estimate of the bathymetry, because the maps made from the spatially dense survey data have smaller errors than the interpolated altimeter data. In between the survey times, the temporally interpolated surveys are a good estimate of bathymetry that changes roughly constantly in time. However, nearshore bathymetric evolution can be highly variable in time, including rapid and large changes during storms when watercraft surveying is not possible. The altimeter maps resolve variable (and rapid) rates of change, but have larger vertical errors than 
the survey maps, which have no bias and average bed-level estimates over a small area. Alternatively, watercraft survey and altimeter bed-level estimates can be combined to create a single set of maps with known accuracy. One approach is to use space-time objective mapping (Bretherton et al. 1976; Ooyama 1987; Rybicki and Press 1992; Plant et al. 1999; Plant et al. 2002) of all the bed-level estimates. Here, an alternative approach is presented that "updates" infrequent watercraft surveys with altimeter data. The spatial pattern of seafloor change is estimated using altimeter data, and added to the mapped watercraft surveys to yield an updated bathymetric estimate at another time. Unlike space-time objective mapping, the maps made using the update method are equal to the spatially mapped surveys at the survey times, and by using the bed-level change estimated by altimeters, rather than the bed level itself, bias errors in the altimeter bed-level estimates are removed.

To implement the update method, first the bed-level change $C_{A}$ at each time $t$ before or after each survey time $t_{S}$ is estimated from the time-mapped altimeter time series:

$$
C_{A}\left(x_{A}, y_{A}, t_{S}, t\right)=Z_{A}\left(x_{A}, y_{A}, t\right)-Z_{A}\left(x_{A}, y_{A}, t_{S}\right)
$$

The error in the change signal $\epsilon_{C A}\left(x_{A}, y_{A}, t\right)$ is assumed to be equal to the error in the mapped time series, $\epsilon_{C A}\left(x_{A}, y_{A}, t\right)=\epsilon_{T}\left(x_{A}, y_{A}, t\right)$. Next, at each time, the change estimates are mapped in space assuming a Gaussian covariance with length scales $L_{x}$ and $L_{y}$, a spatially uniform variance $V_{C}$ [estimated from the change $C_{A}\left(x_{A}, y_{A}, t_{S}, t\right)$ between $t_{S}$ and $\left.t\right]$, and an observation error $\epsilon_{C A}$. No mean or trend is removed from $C_{A}\left(x_{A}, y_{A}, t_{S}, t\right)$ prior to mapping, so that the change signal estimate approaches zero far from observations. This process yields a gridded estimate of the change $C\left(x, y, t_{s}, t\right)$ since each survey with estimated errors $\epsilon_{C}\left(x, y, t_{S}, t\right)$.

Each mapped spatially dense survey is "updated" to other times by adding the mapped change:

$$
Z_{U}\left(x, y, t_{S}, t\right)=Z_{S}\left(x, y, t_{S}\right)+C\left(x, y, t_{S}, t\right)
$$

The error of the updated map is estimated as a sum of the errors of the survey and the change signal:

$$
\epsilon_{U}\left(x, y, t_{S}, t\right)=\epsilon_{S}\left(x, y, t_{S}\right)+\epsilon_{C}\left(x, y, t_{S}, t\right)
$$

The method described in Eq. 2 "updates" a spatially dense survey either forward or backward in time to form an estimate of the bathymetry at another time. This method is referred to as the forward-backward update method. 
When multiple dense surveys are available, a weighted-update method may be used. The bathymetry at each time $Z_{U W}(x, y, t)$ is computed as a weighted sum of the maps updated from each survey:

$$
Z_{U W}(x, y, t)=\sum_{t_{S}} W\left[Z_{S}\left(x, y, t_{S}\right)+C\left(x, y, t_{S}, t\right)\right]
$$

where $W$ are the weights. The errors are estimated as a weighted sum of the errors of the updated maps:

$$
\epsilon_{U W}(x, y, t)=\sum_{t_{S}} W\left[\epsilon_{S}\left(x, y, t_{S}\right)+\epsilon_{C}\left(x, y, t_{S}, t\right)\right]
$$

The weights chosen here are proportional to the time separation between the time of interest $t$ and the survey times $t_{S}$, with the weights for the surveys immediately preceding and following the time $t$ summing to one, and all other surveys weighted zero. For this choice of inverse distance weighting, the bathymetric estimate at survey times is equal to $Z_{S}\left(x, y, t_{S}\right)$. Between survey times, the bed-level estimate approaches the mapped altimeter bed-level estimate at time $t$ plus a weighted offset between the mapped altimeter bed-level estimates and the surveys at the nearest survey times (note that $C\left(x, y, t_{S}, t\right) \approx Z_{A}(x, y, t)-Z_{A}\left(x, y, t_{S}\right)$ ). The bathymetric estimate far (several times $L_{x}$ or $L_{y}$ ) from altimeters approaches a weighted sum of the surveys (note that the mapped $C\left(x, y, t_{S}, t\right)$ approaches zero far from the altimeters).

\subsection{Method assessment}

In addition to comparing the estimated interpolation errors, the methods are tested by comparing the mapped estimates with an independent estimate of the true bathymetry. A mapped survey at a particular survey time is set aside as independent "ground truth" for the methods attempting to reconstruct the bathymetry at that time. Comparisons are made only in the region for which the surveys have errors below a specified threshold (in regions with poor survey coverage, the mapped survey may not be an accurate representation of the true bathymetry). At each time, the differences (at the set of spatial mapping coordinates) between the true bathymetry and a mapped bathymetric estimate are referred to as the "reconstruction residuals," and the rms residuals are referred to as the "reconstruction errors" $\epsilon_{R}$. The average reconstruction error over all comparisons is denoted $\overline{\epsilon_{R}}$. For the forward-backward update method (Eq. 2), only one 
watercraft survey is used with the altimeters to estimate the bathymetry, and all other surveys are used as ground truth. For the weighted update method (Eq. 4), as well as for temporally interpolating between two dense surveys, the ground truth survey is one that was obtained between two other surveys that are used to reconstruct the bathymetry at any time between them. Thus, any combination of three surveys can be used to test the weighted-update and the temporal-interpolation methods. The first and last surveys are used to estimate the bathymetry at the time of the middle survey, which is the ground truth.

\section{Rip channel bathymetric estimates}

\subsection{Overview of field observations and mapping of dredged rip channels}

The propellers from a Vietnam-era landing craft were used to dredge large shore-perpendicular channels in 1- to 3-m water depth on a long straight Atlantic Ocean beach at the US Army Corps of Engineers Field Research Facility near Duck, NC, USA. Five channels were dredged in July and August 2012 (Fig. 2 shows two of the five channels). Pressure sensors colocated with current meters (both sampled at $2 \mathrm{~Hz}$ ) and current profilers (1-minute averages) were deployed near the bed in and outside of the channels (Fig. 2), and bathymetric evolution was recorded by a watercraft survey system and altimeters. The channels were on average 2-m deep, 30-m wide in the alongshore, and 50-m long in the cross-shore. The ambient bathymetry was either a terrace (e.g., Fig. 2c,d,e,f) or a small sandbar (0.5-1 m trough to crest) (e.g., Fig. 2a,b on the south side of the channel), and the average tidal range was $1 \mathrm{~m}$. Bedforms observed by divers and documented in detail for previous studies at this site included small wave ripples and larger-scale megaripples with heights of order 0.1-0.5 m (rms amplitude $\sim 0.1 \mathrm{~m}$ ), horizontal length scales of order 1-10 m, and propagation speeds of 0.3-1.2 m/hr (Gallagher et al. 1998b; Gallagher et al. 2005). Significant wave heights [4 times the standard deviation (std dev) of sea-surface-elevation fluctuations in the frequency $(f)$ band $0.05<f<0.30 \mathrm{~Hz}$ ] just offshore of the channels ranged from 0.5 to $1.5 \mathrm{~m}$ and wave directions (Kuik et al. 1988) ranged from approximately -35 to +35 degrees relative to shore normal. Both rip current circulation patterns $(0.1$ to $1.0 \mathrm{~m} / \mathrm{s}$ houraveraged jet speeds) and alongshore flows over the channels $(0.1$ to $1.0 \mathrm{~m} / \mathrm{s}$ hour-averaged speeds) were observed, and the bathymetry tended to evolve rapidly in response to the larger 
waves and stronger flows (Moulton et al. 2013).

Surveys were performed daily with a personal watercraft (waverunner) except when waves were too large for safe operations. The 24 personal watercraft surveys for the 5 channel experiments ( 3 surveys each for the 2 channels shown in Fig. 2, and 6 surveys each for the other 3 channels) spanned roughly $200 \mathrm{~m}$ in the alongshore (centered at the channels), and extended from the mean shoreline (surveys usually were performed at high tide) to about 100 to $200 \mathrm{~m}$ offshore (Moulton et al. 2013). The 1- to 3-hr long surveys were conducted along cross- and alongshore oriented tracks, each separated by approximately $5 \mathrm{~m}$ with a sample every $0.1 \mathrm{~m}$ along each track.

To study the coupled evolution of the channels and flows, the survey data were mapped (Fig. 2) to a 2-m spatial grid $(x, y)$ spanning $100 \mathrm{~m}$ in the alongshore (centered at the channels) and 100 $\mathrm{m}$ in the cross shore (approximately from the mean shoreline to 3-m water depth). The surveys were mapped as a deviation from an average linear beach slope for each channel location (average slopes found from a fit to all observations for each channel location ranged from 0.019 to 0.025 ). To speed the computations, raw survey data were averaged over $2 \times 2 \mathrm{~m}$ bins prior to mapping. The error in each bin is estimated as the sample error divided by the square root of the number of observations in the bin. The binned data were mapped using scale-controlled objective mapping with $L_{x}=L_{y}=9 \mathrm{~m}, V_{S}=0.08 \mathrm{~m}^{2}$, and an observation error (prior to binning) of $\epsilon_{O}=$ $0.20 \mathrm{~m}$. The decorrelation scales are found from Gaussian fits to the autocovariance of cross- and alongshore bathymetric profiles, and on average were $5 \mathrm{~m}$ in the cross-shore (std dev $=2 \mathrm{~m}$ ) and $6 \mathrm{~m}$ in the alongshore ( $\operatorname{std} \mathrm{dev}=2 \mathrm{~m}$ ). Across the deepest channel cross-sections, the alongshore decorrelation scale is on average $9 \mathrm{~m}(\mathrm{std} \mathrm{dev}=2 \mathrm{~m})$. Here, $L_{x}=L_{y}=9 \mathrm{~m}$ are used in the mapping to resolve the rip channels and smooth over smaller features (megaripple wavelengths may be $1-10 \mathrm{~m}$ ). The variance $V_{S}$ is the average variance of the deviations of smooth bathymetric estimates from the mean beach slope (estimated using all observations). The observation error $\epsilon_{O}$ was chosen to account for vertical errors in the bed location $(0.10 \mathrm{~m})$ and for the amplitude of unresolved features $(0.10 \mathrm{~m}$ rms bedform amplitude). The result is 24 bathymetric estimates (at the survey times) $Z_{S}\left(x, y, t_{S}\right)$ (Fig. 2, contours) and a corresponding set of error estimates $\epsilon_{S}\left(x, y, t_{S}\right)$ (Fig. 2, colors). The errors for the surveys are small ( 0.02 m) except near the shoreline where survey tracks are sparse or absent. An estimate of the bathymetry between 
survey times on a 1-hour time $(t)$ grid $\left[Z_{S}(x, y, t)\right]$ spanning the observational record was found using the temporal-inverse-distance weighting described in Section 3.1. The error in $Z_{S}(x, y, t)$ is expected to be equal to $\epsilon_{S}\left(x, y, t_{S}\right)$ at the survey times and increase quadratically with increasing time separation from surveys, and thus to become larger than the signal variance when more than one decorrelation time scale away from any survey (e.g., Mastroianni and Milovanović 2008), but no formal error estimate is made here.

Estimates of the seafloor elevation were obtained every minute from an array of altimeters (as few as 3 and as many as 14 sensors) with roughly 5 to $30 \mathrm{~m}$ spacing centered at the channel (arrays for two channels are shown in Fig. 2, the 3 channels not shown had 10-14 altimeters in an array similar to that shown in Fig. 2d,e,f). The arrays were designed to resolve the flows and bathymetry in the rip channels [expected to have scales of $\mathrm{O}(10 \mathrm{~m})$ in the cross- and alongshore directions] and on the adjacent cross-shore terrace and bar structure [expected to have scales of $\mathrm{O}(10 \mathrm{~m})$ in the cross-shore and scales of $\mathrm{O}(50 \mathrm{~m})$ or longer in the alongshore far from the channels]. Sensors were spaced most densely across the channels, where the flows and bathymetry were expected to vary most rapidly in space and time. Two types of acoustic altimeters were deployed. At most locations, the bed level was estimated with the single-beam acoustic altimeters recently developed at WHOI, and at a few locations the bed elevation was estimated using a downward-looking Nortek Aquadopp profiler mounted above the seafloor. The altimeter time series are mapped in time to the 1-hour grid $t$ with a scale-controlled objective mapping method with $T=6$ hours, $V_{T}=0.08 \mathrm{~m}^{2}$ (the average variance estimated from all observations), and measurement rms error $\epsilon_{r m s}=0.10 \mathrm{~m}$ (assumed the same for both types of altimeters). The timescale $T$ was chosen to resolve the fastest migration events, and is large enough to average over several periods of most migrating bedforms [although some bedforms may take as long as 36 hours to pass under each altimeter (Gallagher et al. 2005)]. The temporal mapping step led to smoothed time series with rms error $\epsilon_{T} \sim 0.013 \mathrm{~m}<\epsilon_{r m s}$. This error may be an underestimate if there are large megaripples (the analysis assumes that the observation errors are correlated on scales smaller than $T$, which is not the case for long, slow-moving bedforms). A bias error (error in the mean, owing to GPS and hand-measurement errors) $\epsilon_{\text {bias }}=$ $0.10 \mathrm{~m}$ is added to the error estimate for each mapped altimeter time series. The time-mapped bed-level estimates are mapped in space (using the same grid as the mapped surveys) as a 

a Gaussian spatial covariance with scales $L_{x}=L_{y}=9 \mathrm{~m}, V_{A}=0.08 \mathrm{~m}^{2}$, and measurement error $\left[\epsilon_{T}+\epsilon_{\text {bias }}\right] \sim 0.11 \mathrm{~m}$. The resulting maps $Z_{A}(x, y, t)$ have estimated errors $\epsilon_{A}(x, y, t)$ ranging from $\sim 0.1 \mathrm{~m}$ near the altimeter locations to $\sim 0.3 \mathrm{~m}$ far from the altimeters.

The survey and altimeter data are combined using the weighted-update method described in Section 3.3 , yielding gridded $(2 \mathrm{~m}, 1 \mathrm{hr})$ estimates of the bathymetry $Z_{U W}(x, y, t)$ and the associated error $\epsilon_{U W}(x, y, t)$. The weighted-update maps have errors that are equal to the survey errors at survey times $\epsilon_{U W}\left(x, y, t_{S}\right)=\epsilon_{S}\left(x, y, t_{S}\right)$, and are smallest near the altimeter locations at all other times. The size of the errors in the updated maps increases with time since a watercraft survey, and is scaled by the variance of the change since the nearest surveys. To test the update method, all possible forward-backward update maps $Z_{U}\left(x, y, t_{S}, t\right)$ (and the corresponding error estimate $\left.\epsilon_{U}\left(x, y, t_{S}, t\right)\right)$ (Eq. 2, using each survey) and all testable weighted-update maps (Eq. 4, using the first and third survey for all possible sets of three surveys) are computed. For comparison with the weighted-update maps, all testable time-interpolated surveys are computed.

\subsection{Assessment of rip channel maps}

The accuracy of maps made with watercraft surveys alone (Sect. 3.2), altimeters alone (Sect. 3.3), and surveys updated with altimeter-estimated change (Sect. 3.4) is assessed for the 24 watercraft surveys ( 3 surveys for each of 2 channels, and 6 surveys each for the other 3 channels) of evolving rip channels. First, the forward-backward updated maps are assessed and compared with the altimeter maps. Next, the weighted-update maps are assessed and compared with the forward-backward updated maps, the altimeter maps, and time-interpolation of surveys. The errors are computed in the region for which survey errors are smaller than $0.05 \mathrm{~m}$ (regions near the shoreline with large survey errors are excluded).

There are 51 pairs (and thus 102 test cases by going forward or backward in time) of temporally separated watercraft surveys, where one survey in the pair is used with Eq. 2 to estimate the bathymetry at the time of the other survey, which is used as ground truth to test the estimate. In addition, bathymetry estimated from altimeter bed levels at the time of the ground truth survey was compared with the ground truth. The forward-backward updated maps have smaller average 
reconstruction errors $\left(\overline{\epsilon_{R, U}}=0.14 \mathrm{~m}\right)$ than the altimeter maps $\left(\overline{\epsilon_{R, A}}=0.18 \mathrm{~m}\right)$. The average rms difference between the pairs of spatially dense surveys is $0.15 \mathrm{~m}$.

There are 62 sets of three temporally separated watercraft surveys, where the first and third survey are used to estimate the bathymetry at the time of the second survey (the ground truth), using inverse-time weighting of the watercraft surveys or by updating with altimeter information either forward in time from the first survey ("forward updated map"), backward in time from the third survey ("backward updated map"), or a weighted combination (Eq. 4). In addition, at the time of the second survey, an altimeter-based estimate of the bathymetry was compared with the second survey. The weighted-update maps have average reconstruction errors $\left(\overline{\epsilon_{R, U W}}=0.08 \mathrm{~m}\right)$ that are smaller than errors in the forward and backward updated maps $\left(\overline{\epsilon_{R, U}}=0.12 \mathrm{~m}\right)$, the altimeter-interpolation maps $\left(\overline{\epsilon_{R, A}}=0.16 \mathrm{~m}\right)$, and temporal interpolation between surveys $\left(\overline{\epsilon_{R, S}}=0.09 \mathrm{~m}\right)$. The average rms difference between final and initial spatially dense surveys is $0.19 \mathrm{~m}$.

As an example, the bathymetry surveyed on 26 July (Fig. 3a) is estimated from a survey 2 days earlier (24 July 12:00, Fig. 2d) and a survey 1 day later (27 July 15:00, Fig. 2f) using the weighted-update (Eq. 4) (Fig. 3b) and altimeter-interpolation (Fig. 3c) methods. The weightedupdate map has smaller errors (Fig. 3b, colors) than the altimeter-interpolation map (Fig. 3c, colors). The rms change between the 24 and 27 July surveys was $0.29 \mathrm{~m}$ (Fig. 3d). The average residuals (difference from the ground truth survey) for the updated map (Fig. 3e) [0.11 m, similar to the average estimated errors $(0.14 \mathrm{~m})$ for the updated map] are smaller than the average residuals for the altimeter map (Fig. 3f) [0.21 m, similar to the average estimated errors $(0.26 \mathrm{~m})$ for the altimeter map]. The spatial pattern of the residuals (Fig. 3e,f, colors) is not consistent with the error estimate (Fig. 3 b,c, colors), likely because the bathymetry varies more rapidly in time (Fig. 3d) and space (Fig. 3a, compare relatively uniform shoals with the channel) near the channels and the shoreline than elsewhere, in contrast with the assumption of a uniform signal variance. The mapping methods and error estimates may be improved by estimating a nonuniform spatial variance (larger at the channel position). However, the channels migrate, and thus a non-uniform spatial variance that is accurate at one time may be a poor estimate at another time. 

shore coordinate nearest the densest cross-channel altimeter spacing) for each of the mapping methods, resulting in an estimate of the channel cross-section every hour for each channel and each method. The cross-sectional profiles may have different error statistics than the twodimensional maps, because the sensor-spacing is denser on average, and the bathymetry may vary more rapidly in space and time for the cross-section of a deep section of the channel than for the full two-dimensional domain. Similar to the two-dimensional maps, the accuracy of the one-dimensional cross-section estimates was compared for time-interpolation of surveys, mapping of altimeter data, and the forward-backward and weighted-update methods.

For the 51 pairs of temporally separated watercraft surveys (102 comparisons), the forwardbackward updated maps have slightly smaller average reconstruction errors $\left(\overline{\epsilon_{R, U}}=0.17 \mathrm{~m}\right)$ than the altimeter maps $\left(\overline{\epsilon_{R, A}}=0.18 \mathrm{~m}\right)$. The average rms difference between final and initial spatially dense surveys is $0.20 \mathrm{~m}$. For the 62 sets of three temporally separated watercraft surveys, the weighted-update maps have average reconstruction errors $\left(\overline{\epsilon_{R, U W}}=0.10 \mathrm{~m}\right)$ that are smaller than the forward and backward updated maps $\left(\overline{\epsilon_{R, U}}=0.15\right)$, the altimeter maps $\left(\overline{\epsilon_{R, A}}=0.15 \mathrm{~m}\right)$, and the weighted surveys $\overline{\epsilon_{R, S}}=0.11 \mathrm{~m}$ ). The average rms difference between pairs of spatially dense surveys is $0.24 \mathrm{~m}$.

The three methods (weighted-update, altimeter-interpolation, and time-interpolation of dense surveys) are used to reconstruct the bathymetry on 30 June (Fig. 4). The survey on 30 June (Fig. 4, solid black) has small errors (Fig. 4, grey shading around black curve), and thus is a good representation of the true bathymetry. The surveys completed 28 June (Fig. 4, dashed black curve) and 5 July (Fig. 4, dotted black curve) are used with altimeter change estimates in the weightedupdate method (Eq. 4) to produce estimates of the bathymetry (Fig. 4, blue curve) and associated errors (Fig. 4, blue shading). Altimeter interpolation also is used to estimate the bathymetry on 30 June (Fig. 4, red curve) and associated errors (Fig. 4, red shading). Interpolating between the surveys on 28 June and 5 July (Fig. 4, green curve) is similar to the weighted-update method (Fig. 4, blue curve). The rms reconstruction error (rms difference with the survey on 30 June) for the weighted-update map is $0.07 \mathrm{~m}$ (similar to the average estimated error $0.08 \mathrm{~m}$ ), for the altimeter 
maps is $0.15 \mathrm{~m}$ (similar to the average estimated error $0.22 \mathrm{~m}$ ), and for the time-interpolation of surveys is $0.07 \mathrm{~m}$. The rms difference between the surveys on 28 June and 05 July is $0.21 \mathrm{~m}$.

\subsection{Application of update method to rip channel cross-section evolution}

The cross-sections of the hourly updated maps can be used to investigate the temporal evolution of the channels between the spatially dense surveys. For the channel dredged on 18 July, dense surveys show that the channel filled and moved northward (toward larger alongshore coordinate) between 20 and 23 July (Fig. 2, compare panels b and c). However, these surveys do not resolve the higher-frequency temporal changes caused by the relatively large waves and rip current that were observed during the several days between dense surveys. In the absence of additional information, it must be assumed the bathymetry evolved uniformly between the times of the dense surveys. In contrast, the cross sections estimated by updating dense surveys with changes observed by the altimeters (Fig. 5, grey curves are every 3 hours) indicate that the rates of channel infill and migration (Fig. 6) varied non-uniformly in time. Gaussian fits to hourly updated cross sections are used as a proxy to determine the channel position (Fig. 6a, usually within one grid cell of the location of the minimum of the profile) and channel depth (Fig. 6b), and (not shown) channel width and ambient bed elevation. Confidence intervals (grey shading in Fig. 6) are found from the distribution of parameters from a series of fits to 300 curves generated by summing the updated maps with random errors drawn from a Gaussian distribution with std dev given by the estimated mapping rms error.

Flows in the rip channel fluctuated with the tidal elevation, with the highest flows occurring near low tide when wave breaking was strongest on the shallow sides. When the channel center moved north of the mid-way point between the center and the northern sensor (Fig. 6a, 21-23 July), the maximum measured offshore-directed flow (not shown) also moved north, from near the center of the channel $(y=662 \mathrm{~m})$ on 21 July to the northern edge of the channel $(y=674 \mathrm{~m})$ (Moulton et al. 2013). The channel filled by almost $1 \mathrm{~m}$ during the 27 hours that the channel center migrated north (from 21 July 12:00 until 22 July 15:00, Figs. 5 and 6). Significant wave heights just offshore of the channel were between 0.5 and $1.0 \mathrm{~m}$, and wave directions were within $15^{\circ}$ of shore normal between 21 July 15:00 and 22 July 06:00, but were more obliquely incident (roughly $35^{\circ}$ from the south) during the previous and following 24 hours. The channel 
may have migrated owing to alongshore divergences in sediment transport by alongshore flows over the channel, and the coupled morphologic and hydrodynamic changes will be the subject of a future study.

\section{Sandbar profile estimates}

\subsection{Overview of field observations and mapping of natural sandbars}

To investigate sandbar migration, 24 spatially dense cross-shore bathymetry profiles were obtained with the CRAB survey system (Birkemeier and Mason 1984) between 25 August and 26 October 1994 at Duck, NC (Thornton et al. 1996; Gallagher et al. 1998a; Birkemeier et al. 2001; and many others). The surveys extended from above the high tide line to roughly 4-m water depth (Fig. 7), with a sample approximately every $1 \mathrm{~m}$ along the cross-shore track. In addition, bed levels were estimated every 3 hours at 10 locations (crosses in Fig. 7) along the transect with altimeters (similar to the WHOI Altimeters described in Sect. 2.2) (Gallagher et al. 1996; Gallagher et al. 1998a). The altimeters were colocated with pressure and velocity sensors. The sensor locations were chosen based on estimates of the cross-shore variability of the nearshore processes investigated. Offshore significant wave heights ranged from 0.5 to $4.0 \mathrm{~m}$. The sandbar was 30 to $80 \mathrm{~m}$ wide, 0.5 to $1 \mathrm{~m}$ high, and migrated both onshore (e.g., Fig. 7 , between 7 and 30 September) and offshore (e.g., Fig. 7, between 25 August and 7 September). The crest of the sandbar migrated more than $100 \mathrm{~m}$ in the cross-shore, between 1.5- and 2.5-m water depths (Fig. 7). Bedforms included small wave-orbital ripples and megaripples with heights of order $0.1-0.5 \mathrm{~m}$ (rms amplitude $\sim 0.1 \mathrm{~m}$ ), horizontal length scales of order 1-10 $\mathrm{m}$, and propagation speeds of 0.3-1.2 m/hr (Gallagher et al., 1998; Gallagher et al. 2005).

The 24 CRAB surveys are mapped as a deviation from a smoothed mean profile (Plant et al. 1999) to a 5-m spatial grid $x$ spanning $350 \mathrm{~m}$ in the cross shore from $x=100 \mathrm{~m}$ to $x=450 \mathrm{~m}$.

The data were mapped using scale-controlled objective mapping with $L_{x}=17 \mathrm{~m}, V_{S}=0.10 \mathrm{~m}^{2}$, and an observation error of $\epsilon_{O}=0.20 \mathrm{~m}$. For cross-shore profiles, the alongshore coordinate $y$ is fixed. The decorrelation scales of the sandbars are found from Gaussian fits to the autocovariance of the bathymetric profiles, and on average were $17 \mathrm{~m}(\mathrm{std} \operatorname{dev} 7 \mathrm{~m})$, a scale that 
resolves the sandbar, while averaging over smaller features. The variance $V_{S}$ is the average variance of the deviations of smooth bathymetric estimates from the smoothed mean profile (estimated using all observations). The observation error $\epsilon_{O}$ was chosen to account for vertical errors in the bed location $(0.10 \mathrm{~m})$ and the amplitude of unresolved features $(0.10 \mathrm{~m} \mathrm{rms}$ bedform amplitude). The result is 24 bathymetric estimates (at the survey times) $Z_{S}\left(x, t_{S}\right)$ (e.g., Fig. 7, curves) and a corresponding set of error estimates $\epsilon_{S}\left(x, t_{S}\right)$ (e.g., Fig. 7, shaded error bars). The errors $\left[\epsilon_{S}\left(x, t_{S}\right)\right]$ for the surveys are small ( 0.05 m, Fig. 7), except for a few cases when survey tracks did not fill the mapping domain and the estimate approaches the mean profile. In those cases the error is as large as, or larger than the signal variance (e.g., Fig. 7, red shading near the most offshore $50 \mathrm{~m}$ of the 7 September survey). Bathymetry on a 6-hour time grid $t$ between survey times $\left[Z_{S}(x, t)\right]$ was estimated using the inverse-temporal weighting described in Section 3.1. The error in $Z_{S}(x, t)$ is expected to be equal to $\epsilon_{S}\left(x, t_{S}\right)$ at the survey times and to increase with increasing time separation from surveys (Mastroianni and Milovanović 2008), but no formal error estimate is made here.

The altimeter time series are mapped to the 6-hour grid $t$ with a scale-controlled objective mapping method with $T=6$ hours, $V_{T}=0.10 \mathrm{~m}^{2}$ (the average variance estimated from all observations), and measurement rms error $\epsilon_{r m s}=0.10 \mathrm{~m}$. The timescale $T$ is short enough to resolve the fastest migration events, and is large enough to average over migrating bedforms. The temporal mapping step led to smoothed time series with smaller rms error $\epsilon_{T} \sim 0.03 \mathrm{~m}$. A bias error (error in the mean, owing to survey-equipment and hand-measurement errors) $\epsilon_{\text {bias }}=$ $0.10 \mathrm{~m}$ is added to the error estimate for each mapped altimeter time series. The time-mapped bed-level estimates are mapped in space (using the same grid as the mapped surveys) as a deviation from a smoothed mean profile (same as the profile removed in the mapped surveys) assuming a Gaussian spatial covariance with scales $L_{x}=17 \mathrm{~m}, V_{A}=0.10 \mathrm{~m}^{2}$, and measurement error $\left[\epsilon_{T}+\epsilon_{\text {bias }}\right] \sim 0.13 \mathrm{~m}$. The resulting maps $Z_{A}(x, t)$ have estimated errors $\epsilon_{A}(x, t)$ ranging from $\sim 0.1 \mathrm{~m}$ near the altimeter locations to $\sim 0.3 \mathrm{~m}$ far from the altimeters.

The survey and altimeter data are combined using the weighted-update method, yielding gridded (5 m, $6 \mathrm{hrs}$ ) estimates of the bathymetry $Z_{U W}(x, t)$ and associated errors $\epsilon_{U W}(x, t)$. To test the update method, all possible forward-backward update maps $Z_{U}\left(x, t_{S}, t\right)$ [and the corresponding 
error estimate $\epsilon_{U}\left(x, t_{S}, t\right)$ ], weighted-update maps $Z_{U W}(x, t)$ (Eq. 4) [and the corresponding error estimate $\left.\epsilon_{U W}(x, t)\right]$, and time-interpolated surveys are computed.

\subsection{Assessment of sandbar profile maps}

The accuracy of the sandbar profile estimates made with CRAB surveys alone, altimeters alone, and surveys updated with altimeter-estimated change is assessed using selected CRAB surveys as independent ground truth. Forward-backward updated maps are assessed and compared with the altimeter maps, and weighted-update maps are assessed and compared with the forwardbackward updated maps, the altimeter maps, and time-interpolation of surveys. The errors are computed in the region for which survey errors are smaller than $0.10 \mathrm{~m}$.

For the 276 pairs of temporally separated watercraft surveys, the forward-backward updated maps have approximately the same average reconstruction errors $\left(\overline{\epsilon_{R, U}}=0.16 \mathrm{~m}\right)$ as the altimeter maps $\left(\overline{\epsilon_{R, A}}=0.16 \mathrm{~m}\right)$. The average rms difference between final and initial spatially dense surveys is $0.38 \mathrm{~m}$. For the 2024 sets of three temporally separated CRAB surveys, the weightedupdate maps have average reconstruction errors $\left(\overline{\epsilon_{R, U W}}=0.12 \mathrm{~m}\right)$ that are smaller than the forward and backward updated maps $\left(\overline{\epsilon_{R, U}}=0.14\right)$, the altimeter maps $\left(\overline{\epsilon_{R, A}}=0.14 \mathrm{~m}\right)$, and the temporally weighted surveys $\overline{\epsilon_{R, S}}=0.21 \mathrm{~m}$ ). The average rms difference between final and initial spatially dense surveys is $0.43 \mathrm{~m}$.

The weighted-update and altimeter-interpolation methods, along with the time interpolation of surveys, are used to reconstruct the bathymetry on 30 September (Fig. 8). The survey on 30 September has small errors (Fig. 8, solid black curve and grey shading), and thus is a good representation of the true bathymetry. The surveys completed at 21 September (Fig. 8, dashed black curve) and 4 October (Fig. 8, dotted black curve) are used with altimeter change estimates in the weighted-update method to produce estimates of the bathymetry (Fig. 8, blue curve) and associated errors (Fig. 8, blue shading). The time-interpolated survey estimate using the 30 September and 4 October surveys also is shown (Fig. 8, green curve), and altimeter interpolation also is used to estimate the bathymetry on 30 September (Fig. 8, red curve) and associated errors (Fig. 8, red shading). The rms reconstruction error (rms difference with the survey on 26 September) for the weighted-update map is $0.08 \mathrm{~m}$ [smaller than the average estimated 
interpolation error (Eq. A7) $0.25 \mathrm{~m}$ ], for the altimeter maps is $0.12 \mathrm{~m}$ (smaller than the average estimated error $0.21 \mathrm{~m}$ ), and for the time-interpolation of surveys is $0.13 \mathrm{~m}$. The rms difference between the surveys on 21 and 30 September is $0.16 \mathrm{~m}$, and between the surveys on 30 September and 4 October is $0.14 \mathrm{~m}$.

\subsection{Application to sandbar migration}

The weighted-update maps improve the temporal resolution of the evolving cross-shore profile, both during rapid bar migration events and during times when conditions precluded CRAB surveys (often simultaneous with rapid bar migration) (Fig. 9). Gaussian fits (summed with a linear beach profile) to six-hour updated profiles are used as a proxy to determine the sandbar crest position (usually within one or two grid cells of the location of the maximum of a detrended profile, Figs. 9 and 10). Confidence intervals (grey shading in Fig. 10) are found from the distribution of parameters from a series of fits to 300 curves generated by summing the updated maps with random errors drawn from a Gaussian distribution with std dev given by the estimated mapping rms error. Infrequent dense surveys show the sandbar migrated about $40 \mathrm{~m}$ offshore between 25 August and 7 September (triangles in Figs. 9 and10). Interpolating between the CRAB surveys assumes the migration was constant in time. However, the updated maps suggest that the offshore migration occurred rapidly between 2 and 6 September (Fig. 10) during a nor'easter storm [3 m significant wave height in $8 \mathrm{~m}$ depth (Gallagher et al. 1998a)], and was preceded by more than one week of slow onshore migration (Fig. 10, 25 August to 2 September). Similarly, during a second nor'easter [14 to 17 October, $4 \mathrm{~m}$ significant wave height in $8 \mathrm{~m}$ depth (Gallagher et al. 1998a)] the updated maps suggest more rapid migration on 15 October than would be inferred from interpolation of the CRAB surveys on 14 and 18 October (Fig. 10). Between 15 and 17 October large waves precluded CRAB surveys of the sandbar.

\section{Discussion and Summary}

Interpolating in time between two spatially dense surveys produces accurate maps of the seafloor assuming the bathymetry changes uniformly in time (for some of the rip channels and some of the bar migration events, e.g., compare green with blue curves in Fig. 4). However, surfzone bathymetry often evolves rapidly and non-uniformly when large waves, strong currents, and 

21.5 in Fig. 6) and the sandbar (2 to 6 September in Fig. 10) in big waves]. In contrast, fixed altimeters can estimate bed levels in the presence of large waves and many bubbles. An array of altimeters sampling continuously can be used to make spatially interpolated bed-level maps at any given time, and may resolve the spatial structure of the bathymetry with reasonable accuracy if altimeter spacing is smaller than the spatial decorrelation scales of the features of interest. However, altimeter spacing can be relatively sparse and the altimeter bed-level estimates can be biased. Here, bed-level estimates from spatially dense, but infrequent surveys were combined with accretion and erosion estimates from spatially sparse, but nearly continuously sampling altimeters to form a bathymetric estimate that is more accurate than either temporally interpolating between two dense surveys or spatially interpolating between the fixed altimeters e.g., Figs. 6 and 10). In studies for which the bathymetric estimate does not need to be independent of hydrodynamic measurements, additional improvements may be made by assimilating hydrodynamic measurements (Wilson et al. 2010; Birrien et al. 2013) along with altimeter bed levels or change signals.

The accuracy of the mapped altimeter change (and therefore of the updated maps) and of the mapped altimeter bed levels is sensitive to the trend removed from the observations prior to mapping (and subsequently added back to the mapped estimate), owing to the tendency of objectively mapped estimates to approach zero far from information (Rybicki and Press 1992, also see Appendix). This tendency can be exploited to improve accuracy where there is insufficient information. Here, the mapped altimeter bed levels far from instrument locations approached a mean beach slope (for the rip channels) or a smoothed mean profile (for the sandbars). The mean slope and smoothed mean profile were found using the dense survey data, so the altimeter bed-level estimates are not strictly independent of the dense surveys. For the maps of bed-level change from altimeters used in the update method, no mean or trend was removed, and thus the estimated change is zero far from altimeters. There are alternatives that may be more appropriate in other applications, such as allowing the change signal estimate far from sensors to approach the average change. 


\begin{abstract}
Although interpolation weights estimated assuming spatially uniform and temporally constant Gaussian covariance functions produced relatively accurate seafloor maps, the patterns of the estimated mapping errors and the errors found in the reconstruction tests did not agree, perhaps because the bathymetry evolves more rapidly and with larger amplitude near the shore and when waves are large. Choosing spatially and temporally variable covariance functions may produce more accurate bathymetric and error estimates. Further investigation of the sensitivity of the estimated and reconstruction errors to the covariance estimates is needed to guide the selection of interpolation weights.
\end{abstract}

Here, the observations of changes in bed level at the locations of fixed altimeters were mapped and added to maps made from occasional spatially dense surveys. When multiple dense surveys were available, updated maps made from each survey were combined in a weighted average. For evolving dredged channels and natural sandbars in the surf zone, the updated maps are a better estimate of the bathymetry than maps made by spatially interpolating altimeter estimates of the bed level or by temporally interpolating dense surveys. 


\section{Appendix. Interpolation and mapping of irregularly sampled observations}

Often, a set of bed-level observations $z\left(x_{j}, y_{j}, t_{j}\right)$, where $x_{j}$ and $y_{j}$ are the cross- and alongshore coordinates of the $j$ th observation made at time $t_{j}$, are mapped using linear interpolation to a regular spatial $\left(x_{i}, y_{i}\right)$ and temporal $\left(t_{i}\right)$ grid:

$$
Z\left(x_{i}, y_{i}, t_{i}\right)=\sum_{j} W_{i j} z\left(x_{j}, y_{j}, t_{j}\right)
$$

where $Z$ is the linearly interpolated bed-level elevation estimate at a set of "mapping coordinates" $\left(x_{i}, y_{i}, t_{i}\right)$ and $W_{i j}$ is the weight of the $j$ th observation at the $i$ th mapping coordinate.

One common choice of interpolation weights is inverse separation weighting, e.g., in time:

$$
W_{i j}=A\left|t_{i}-t_{j}\right|^{-1}
$$

The factor $A$ (which may be a function of the observation and mapping coordinates) is sometimes set such that the only observations with nonzero weights are those immediately preceding and following the mapping coordinate, and may be normalized by the sum of the weights such that weights at each mapping coordinate sum to one.

Other mapping methods take advantage of knowledge of the signal covariance to seek an estimate of the bathymetry that minimizes the root-mean-square (rms) difference between the true and the mapped bathymetry (Bretherton et al. 1976). Optimal weights are:

$$
W_{i j}=\sum_{j^{\prime}}\left[P_{j^{\prime} j}\right]^{-1} R_{j^{\prime} i}
$$

where $P_{j \prime} j$ is the covariance between observed elevations at locations with indices $j^{\prime}$ and $j, R_{j \prime i}$ is the covariance between observed and mapped elevations, and []$^{-1}$ is the matrix inverse. This method is referred to as objective mapping or optimal interpolation. Often a Gaussian model for the covariance is used for mapping either in space or in time, e.g., in one dimension:

$$
R_{m n}=V \exp \left(-\frac{\left(p_{m}-p_{n}\right)^{2}}{2 L^{2}}\right)
$$

where $V$ is the estimated signal variance, $p$ is the spatial or time coordinate, $m$ and $n$ are arbitrary indices, and $L$ is a decorrelation length or time scale. The covariance between all observed elevations is:

$$
P_{j^{\prime} j}=R_{j^{\prime} j}+\epsilon_{O,}^{2}\left(x_{j}, y_{j}, t_{j}\right) \delta_{j^{\prime} j}
$$


where $\epsilon_{O}\left(x_{j}, y_{j}, t_{j}\right)$ is the rms observational error associated with the $j$ th observation. It is assumed that observation errors are uncorrelated with errors at other locations and times (the delta function $\delta_{j^{\prime} j}=0$ if $j^{\prime} \neq j$, and $\delta_{j^{\prime} j}=1$ if $j^{\prime}=j$ ).

Often a mean or trend $M$ is removed before mapping and then added back in after mapping (this can be considered a scale separation):

$$
Z\left(x_{i}, y_{i}, t_{i}\right)=\sum_{j} W_{i j}\left[z\left(x_{j}, y_{j}, t_{j}\right)-M\right]+M
$$

The function $M$ may be an estimate of the true signal mean, a linear trend, a higher-order trend, or an ensemble-averaged estimate of a mean state. The choice becomes particularly important for data that are under-sampled because far from observations the interpolation weights tend to approach zero, and thus the bathymetric estimate approaches $M$ (Rybicki and Press 1992).

The estimated interpolation error is:

$$
\epsilon\left(x_{i}, y_{i}, t_{i}\right)=V-\sum_{j} W_{i j} R_{i j}
$$

If there are small-scale features (e.g., ripples, megaripples, cusps) that are not resolved by the surveys (e.g., there is aliasing owing to undersampling) or are not desired in the estimate of the bathymetry (e.g., considered noise), weights may be derived to minimize the rms difference between the mapped bathymetry and a filtered (e.g., smoothed) true bathymetry (Ooyama 1987; Plant et al. 1999). When seeking the optimal estimate of smoothed bathymetry, smoothed covariance functions of the true bathymetry (Ooyama 1987) are used. Here, the covariance function is assumed to be a Gaussian (Eq. A5) with the scale $L$ set to the smoothing scale (a resolvable scale of interest) and the signal variance $V$ set to the estimated variance of the smoothed bathymetry. In the presence of unresolved scales, $\epsilon_{O}$ should include both the rms measurement error and an rms estimate of the error associated with unresolved scales (e.g., the rms amplitude of bedforms). The results are optimal only if the covariance function is chosen correctly (e.g., a spatially variable covariance function could be used), but more detailed information about the true bathymetry would be needed to improve the covariance function estimate, and it is expected that the interpolation errors are not highly sensitive to errors in the choice of covariance function (Rybicki and Press 1992). 


\section{Acknowledgements}

The US Army Corps of Engineers Field Research Facility (Duck, NC, USA) provided excellent logistical support for both the 1994 and 2012 datasets. We thank Brian Scarborough and Jason Pipes for driving the landing craft and making depressions in the surfzone seafloor, and Jesse McNinch and the FRF team for their generous hospitality. We also thank Bill Boyd, David Clark, Danik Forsman, Dana Giffen, Levi Gorrell, Jeff Hansen, Julia Hopkins, Sean Kilgallin, Christen Rivera-Erick, Jenna Walker, Anna Wargula, Regina Yopak, and Seth Zippel for their tenacity in the field. Peter Traykovski and Fred Jaffre designed and built the WHOI altimeters. Falk Feddersen, Edith Gallagher, Robert Guza, Thomas Herbers, the Scripps Center for Coastal Studies field crew, and many others helped gather the Duck94 data. This work was funded by the Office of the Assistant Secretary of Defense for Research and Engineering, a National Defense Science and Engineering Graduate Fellowship, A National Science Foundation Graduate Research Fellowship, the National Science Foundation, and the Office of Naval Research. 


\section{References}

Austin M, Scott T, Brown Jeff, Brown Jenna, MacMahan J, Masselink G, Russell P (2010) Temporal observations of rip current circulation on a macro-tidal beach. Continental Shelf Res 30:1149-1165. doi:10.1016/j.csr.2010.03.005

Birkemeier WA, Mason C (1984) The CRAB: A unique nearshore surveying vehicle. J Surveying Eng 110(1):1-7. doi:10.1061/(ASCE)0733-9453(1984)110:1(1)

Birkemeier WA, Long C, Hathaway K (2001) DELILAH, DUCK94 \& SandyDuck: Three Nearshore Field Experiments. Coast Eng Proc ASCE 1(25):4052-4065. doi:10.9753/icce.v25

Birrien F, Castelle B, Marieu V, Dubarbier B (2013) On a data-model assimilation method to inverse wave-dominated beach bathymetry using heterogeneous video-derived observations. Ocean Eng 73:126-138. doi:10.1016/j.oceaneng.2013.08.002

Bretherton, FP, Davis RE, Fandry CB (1976) A technique for objective analysis and design of oceanographic experiments applied to MODE-73. Deep-Sea Res 23:559-582. doi:10.1016/0011-7471(76)90001-2

Chen Q, Dalrymple R, Kirby J, Kennedy A, Haller M (1999) Boussinesq modeling of a rip current system. J Geophys Res 104(C9):20617-20637. doi: 10.1029/1999JC900154

Dalrymple R, MacMahan J, Reniers A, Nelko V (2011) Rip Currents. Annual Rev Fluid Mech 43:551-581. doi:10.1146/annurev-fluid-122109-160733

Dugan J, Morris W, Vierra K, Piotrowski C, Farruggia G, Campion D (2001) Jetski-based nearshore bathymetric and current survey system. J Coastal Res 17(4):900-908.

Elgar S, Gallagher EL, Guza RT (2001) Nearshore sandbar migration. J Geophys Res 106:11623-11627. doi:10.1029/2000jc000389

Falqués A, Coco G, Huntley DA (2000) A mechanism for the generation of wave-driven rhythmic patterns in the surf zone. J Geophys Res 105(C10):24071-24088. doi:10.1029/2000JC900100

Feddersen F, Gallagher EL, Guza RT, Elgar S (2003) The drag coefficient, bottom roughness, and wave breaking in the nearshore. Coastal Eng 48:189-195. doi:10.1016/s03783839(03)00026-7

Gallagher E, Boyd W, Elgar S, Guza R, Woodward B (1996) Performance of a sonar altimeter in the nearshore. Marine Geol 133:241-248. doi:10.1016/0025-3227(96)00018-7 
Gallagher E, Elgar S, Guza R (1998a) Observations of sand bar evolution on a natural beach. J Geophys Res 103:3203-3215. doi:10.1029/97JC02765

Gallagher E, Elgar S, Thornton E (1998b) Megaripple migration in a natural surfzone. Nature 394:165-168. doi:10.1038/28139

Gallagher EL, Elgar S, Guza RT, Thornton, EB (2005) Estimating nearshore bedform amplitudes with altimeters. Marine Geol 216(1):51-57. doi:10.1016/j.margeo.2005.01.005

Gallop SL, Bryan KR, Coco G, Stephens SA (2011) Storm-driven changes in rip channel patterns on an embayed beach. Geomorph 127:179-188. doi:10.1016/j.geomorph.2010.12.014

Garnier R, Falqués A, Calvete D, Thiébot J, Ribas F (2013) A mechanism for sandbar straightening by oblique wave incidence. Geophys Res Lett 40. doi:10.1002/grl.50464

Genton MG (2007) Separable approximations of space-time covariance matrices. Environmetrics 18(7):681-695. doi:10.1002/env.854

Haller M, Dalrymple R, Svendsen I (2002) Experimental study of nearshore dynamics on a barred beach with rip channels. J Geophys Res 107(C6):3061. doi:10.1029/2001JC000955

Henderson S, Allen J, Newberger P (2004) Nearshore sandbar migration predicted by an eddydiffusive boundary layer model. J Geophys Res 109. doi:10.1029/2003JC002137

Hoefel F, Elgar S (2003) Wave-induced sediment transport and sandbar migration. Science 299:1885-1887. doi:10.1126/science. 1081448

Holland KT, Holman RA, Lippmann TC, Stanley J, Plant N (1997) Practical use of video imagery in nearshore oceanographic field studies. IEEE J Oceanic Eng 22:81-92. doi: $10.1109 / 48.557542$

Holman RA, Sallenger AH, Lippmann TC, Haines JW (1993) The application of video image processing to the study of nearshore processes. Oceanogr 6:78-85. doi:10.5670/oceanog.1993.02

Holman RA, Symonds G, Thornton EB, Ranasinghe R (2006) Rip spacing and persistence on an embayed beach. J Geophys Res 111:C01006. doi:10.1029/2005JC002965

Holman RA, Haller MC (2013) Remote Sensing of the Nearshore. Annual Rev of Mar Sci, 5(1):95-113. doi:10.1146/annurev-marine-121211-172408

Holman R, Plant N, Holland T (2013) cBathy: A robust algorithm for estimating nearshore bathymetry. J Geophys Res 118:2595-2609. doi:10.1002/jgrc.20199, 2013 
Hsu T-J, Elgar S, Guza R (2006) Wave-induced sediment transport and onshore sandbar migration. Coastal Eng 53:817-824. doi:10.1016/j.coastaleng.2006.04.003

Kuik A, van Vledder G, Holthuijsen L (1988) A method for the routine analysis of pitch-and-roll buoy wave data. J Phys Oceanogr 18:1020-1034. doi:10.1175/15200485(1988)018<1020:AMFTRA>2.0.CO;2

Lippmann T, Holman R (1989) Quantification of sand-bar morphology: a video technique based on wave dissipation. J Geophys Res 94(C1):995-1011. doi:10.1029/JC094iC01p00995

Lippmann T, Smith G (2008) Shallow surveying in hazardous waters. Shallow Water Survey Conf, Durham, NH, USA.

MacMahan J (2001) Hydrographic surveying from personal watercraft. J Surv Eng 127(1):12-24. doi:10.1061/(ASCE)0733-9453(2001)127:1(12)

MacMahan J, Thornton E, Reniers A (2006) Rip current review. Coastal Eng 53:191-208. doi:10.1016/j.coastaleng.2005.10.009

Mastroianni G, Milovanović GV (2008) Interpolation Processes: Basic Theory and Applications. Springer, Berlin. doi:10.1007/978-3-540-68349-0

Moulton M, Elgar S, Raubenheimer B (2013) Structure and evolution of dredged rip channels. Proc of Coastal Dynamics '13, ASCE, Arcachon, Fr. 1263-1274

Ooyama KV (1987) Scale-Controlled Objective Analysis. Mon Weather Rev 115:2479-2506. doi:10.1175/1520-0493(1987)115<2479:SCOA>2.0.CO;2

Plant NG, Holman RA, and Freilich MH (1999) A simple model for interannual sandbar behavior. J Geophys Res 104(C7):15755-15776. doi:10.1029/1999JC900112

Plant NG, Holland KT, Puleo JA (2002) Analysis of the scale errors in nearshore bathymetric data. Marine Geol 191:71-86. doi:10.1016/S0025-3227(02)00497-8

Plant NG, Edwards K, Kaihatu J, Veeramony J, Hsu L, Holland K (2009) The effect of bathymetric filtering on nearshore process model results. Coast Eng 56:484-493. doi:10.1016/j.coastaleng.2008.10.010

Ruessink BG, van Enckevork IMJ, Kingston KS, Davidson MA (2000) Analysis of observed two- and three-dimensional nearshore bar behavior. Marine Geol 169:161-183. doi:10.1016/S0025-3227(00)00060-8

Rybicki GB, Press WH (1992) Interpolation, realization, and reconstruction of noisy, irregularly sampled data. Astrophys J 398:169-176. 
Thornton E, Humiston R, Birkemeier W (1996) Bar/trough generation on a natural beach. J Geophys Res 101(C5):12097-12110. doi:10.1029/96JC00209

van Dongeren A, Plant N, Cohen A, Roelvink D, Haller MC, Catalán P (2008) Beach Wizard:

Nearshore bathymetry estimation through assimilation of model computations and remote observations. Coastal Eng 55(12):1016-1027. doi:10.1016/j.coastaleng.2008.04.011

van Enckevort IMJ, Ruessink BG (2003) Video observations of nearshore bar behaviour. Part 2: alongshore non-uniform variability. Continental Shelf Res 23:513-532. doi:10.1016/S02784343(02)00235-2

van Enckevort IMJ, Ruessink BG, Coco G, Suzuki K, Turner IL, Plant NG, Holman RA (2004) Observations of nearshore crescentic sandbars. J Geophys Res 109:C06028. doi:10.1029/2003JC002214

Wilson GW, Özkan-Haller HT, Holman RA (2010) Data assimilation and bathymetric inversion in a two-dimensional horizontal surf zone model. J Geophys Res 115:C12057. doi:10.1029/2010JC006286 


\section{Figure Captions}

Fig. 1 Amplitude of acoustic returns from the WHOI altimeter (color scale on right) as a function of depth below the altimeter $(\Delta \mathrm{z})$ and time for (a) 7 days (black curve is seafloor location) and (b) 3 minutes of data. The * on the time axis of (a) (between time $=4$ and time $=5$ days) corresponds to the time of the time series in (b)

Fig. 2 Contours of mapped water depth (relative to mean sea level, black curves every $0.5 \mathrm{~m}$ in depth, the thick curves are $-1.5 \mathrm{~m}$ ) and estimated interpolation errors (colors, scale on right) from watercraft surveys for channels dredged on 18 July (top row: a, b, c) and 24 July 2012 (bottom row: $\mathrm{d}, \mathrm{e}, \mathrm{f}$ ) as a function of cross- and alongshore coordinate, with the shoreline on the left side of each panel and north toward the top. The survey times for the first dredged channel are (a) 18 July 18:00 EDT (shortly after dredging), (b) 20 July 10:00, and (c) 23 July 12:00. The survey times for the second dredged channel are (d) 24 July 12:00 (shortly after dredging), (e) 26 July 14:00, and (f) 27 July 15:00. Crosses show positions of altimeters, which were colocated with a pressure gauge and a current meter or current profiler. Three other dredged channels (not shown) had arrays similar to the channel dredged on 24 July (d, e, f). For all survey maps the errors usually are 0.01-0.05 cm, except near the shoreline where the density of survey tracks (not shown) was reduced and errors are as great at $0.3 \mathrm{~m}$

Fig. 3 Contours of mapped water depth (relative to mean sea level, black curves every $0.5 \mathrm{~m}$ in depth, the thick contours are $-1.5 \mathrm{~m}$ ) and errors (colors, scale on right) on 26 July 14:00 for (a) a mapped watercraft survey, (b) a weighted-update map (surveys at 24 July 12:00 and 27 July 15:00 are used to form the estimate, see Fig. 2d,f), and (c) an altimeter map. (d) The mapped watercraft survey on 26 July 14:00 (black contours) and the magnitude of change between the surveys on 24 July 12:00 and 27 July 15:00, and (e and f) contours of water depth (black contours) and magnitude of residuals with the survey on 26 July 14:00 using (e) a weightedupdate map and (f) an altimeter map. All maps are a function of cross- and alongshore coordinate, with the shoreline on the left side of each panel. Crosses show positions of altimeters 
Fig. 4 Depth of seafloor across the channel versus alongshore coordinate from watercraft surveys on 28 June 13:00 (black dashed curve), 30 June 07:00 (ground truth, solid black curve), and 5 July 12:00 (dotted black curve), and estimated for 30 June 07:00 using the weighted-update (blue curve), altimeter-interpolation (red curve), and time-interpolation of the 28 June and 05 July surveys (green curve). Shaded areas are $1 \mathrm{std}$ dev errors for the estimated bathymetries. Crosses show alongshore positions of altimeters

Fig. 5 Depth of the seafloor across the channel versus alongshore coordinate. The solid black curve is the cross-section from the watercraft survey on 18 July 18:00, the dashed black curve is from the survey on 20 July 10:00, and the dotted black curve is from the survey on 23 July 12:00. Grey, red, green, and blue curves are cross sections using the weighted-update method every 3 hours between 18 July 18:00 and 23 July 12:00. The channel fills and migrates northward most rapidly on 21 July from 12:00 (red curve), through 15:00 (green curve), and until 18:00 (blue curve). Crosses at depth $=-1 \mathrm{~m}$ are alongshore positions of altimeters, and the other symbols below the crosses are the alongshore position of the channel (estimated by fit to a Gaussian) for surveys (circle and triangles) and updated maps for 21 July 12:00 (red star), 15:00 (green diamond), and 18:00 (blue square)

Fig. 6 (a) Alongshore position of the channel center and (b) channel depth based on altimeterupdated cross sections (curves with shaded 95\% confidence interval) and watercraft surveys (circles and triangles) versus time (date in July, labeled tick marks at 00:00). Crosses on the yaxis in (a) show alongshore positions $(y=662$ and $y=674 \mathrm{~m})$ of the two nearest altimeters. The most rapid change in the channel (infill and northward migration, found from Gaussian fits, also see Fig. 5) occurred beginning 21 July from approximately 12:00 (red star), through 15:00 (green diamond), until 18:00 (blue square)

Fig. 7 Depth of the seafloor (relative to mean sea level) versus cross-shore coordinate for spatially dense CRAB surveys (curves with shaded one std dev error estimates) for 25 August (black), 7 September (red), 30 September (green), and 26 October (blue) 1994. Crosses at depth $=0 \mathrm{~m}$ are cross-shore positions of altimeters 

September (ground truth, solid black curve), and 4 October (dotted black curve), and estimated for 30 September using the weighted-update (solid blue curve), altimeter-interpolation (red solid curve), and time-interpolation of the 21 September and 4 October CRAB surveys (green solid curve) methods. Shaded areas are $1 \mathrm{std}$ dev error estimates (errors for 21 September and 4 October are similar to the grey shading shown for 30 September) and the estimated bathymetries. Crosses show cross-shore positions of altimeters

Fig. 9 Depth of seafloor (relative to a smoothed mean profile that is removed from each map) across the sandbar versus cross-shore coordinate (the shoreline is near cross-shore coordinate $100 \mathrm{~m}$ ). The solid black curve is the initial watercraft survey on 25 August 1994, and the dotted black curve is the survey on 7 September. Grey, red, green, and blue curves are cross-shore profiles using the weighted-update method every 12 hours between 25 August and 7 September. The sandbar migrated most rapidly on 2 September (red curve), through 4 September (green curve), and until 6 September (blue curve). Crosses at depth $=-1 \mathrm{~m}$ are cross-shore positions of altimeters, and the symbols below the crosses are the bar crest position (estimated by a fit to a linear slope plus a Gaussian) for surveys on 25 August (upward triangle) and 7 September (downward triangle) and updated maps for 2 (red star), 4 (green diamond), and 6 September (blue square)

Fig. 10 (a) Cross-shore position of the sandbar crest based on altimeter-updated profiles every 3 hours (grey curve with shaded $95 \%$ confidence interval) and on spatially dense CRAB surveys (black circles and triangles) versus time. The shoreline is near cross-shore position $100 \mathrm{~m}$. Crosses along the $y$-axis are cross-shore positions of the altimeters. A rapid bar migration event (also see Fig. 9) occurred from 2 to 6 September, between the surveys on 25 August (upwardpointing triangle) and 7 September (downward triangle). The bar cross-shore position moved rapidly starting on 2 September (red star), through 4 September (green diamond), until 6 September (blue square) 


\section{Fig1}

Click here to download Manuscript: Fig1.eps

Click here to view linked References

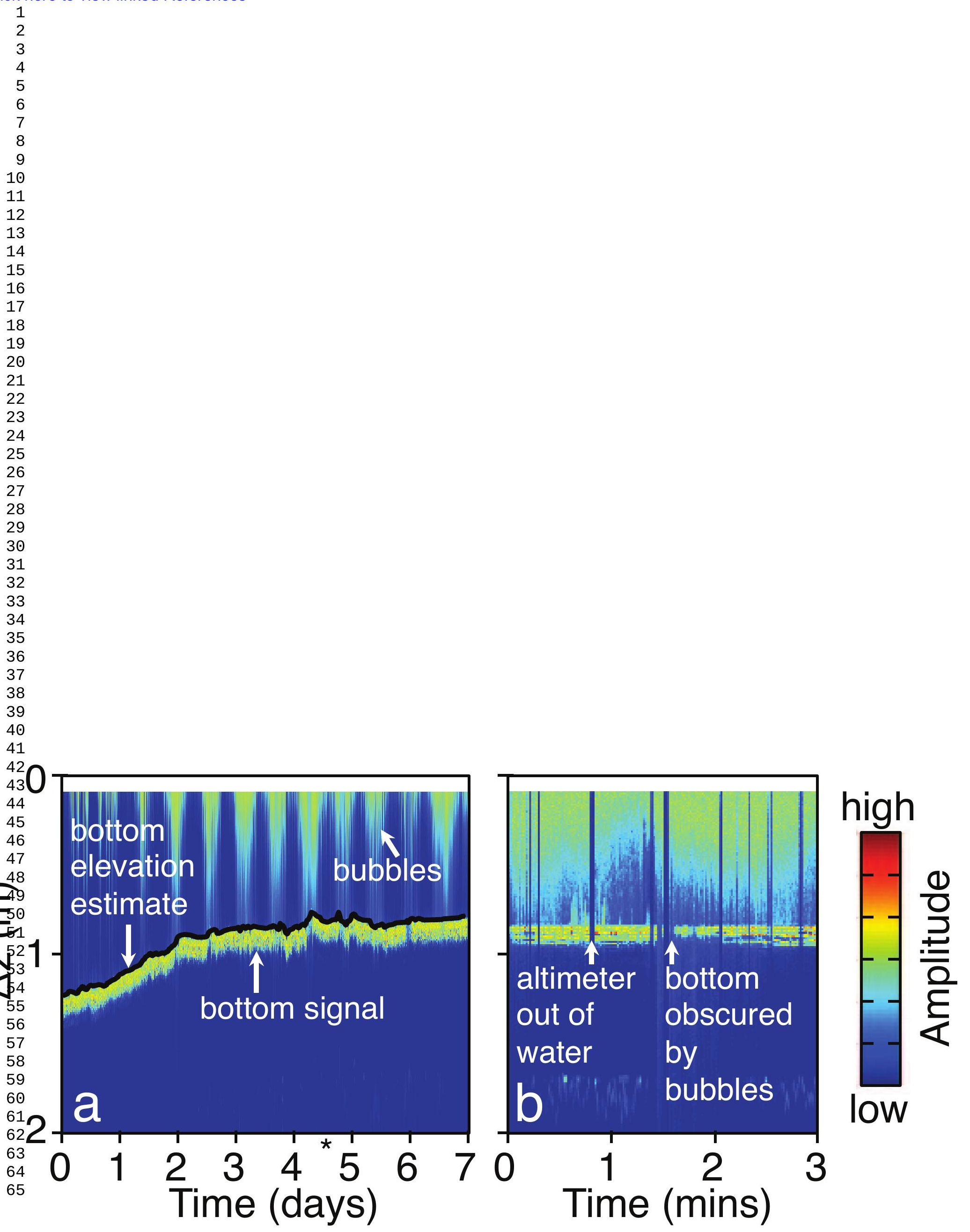

0

4 1 


\section{Fig2}

Click here to download Manuscript: Fig2.eps

Click here to view linked References

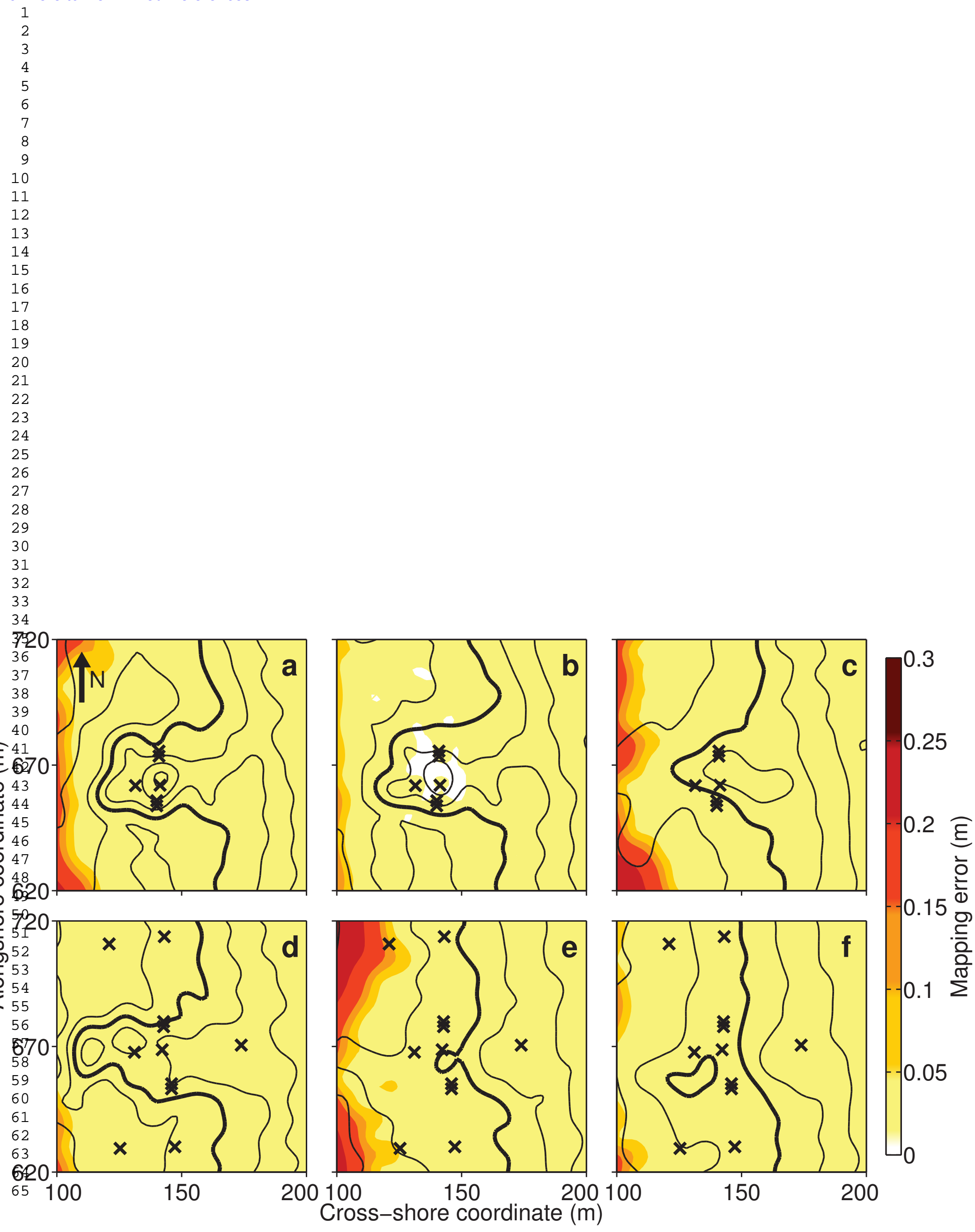


Click here to download Manuscript: Fig4.eps

Click here to view linked References

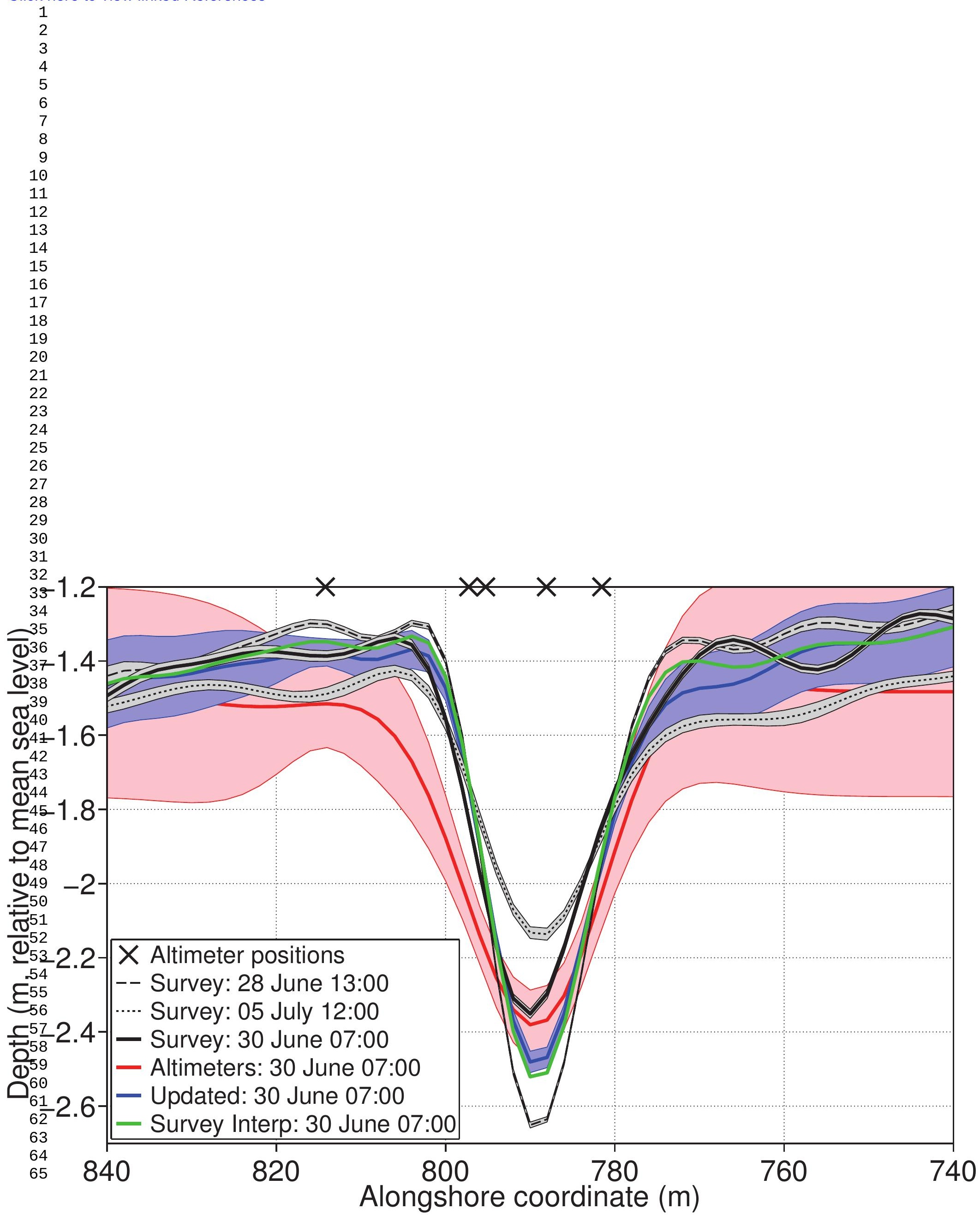


Click here to download Manuscript: Fig5.eps

Click here to view linked References

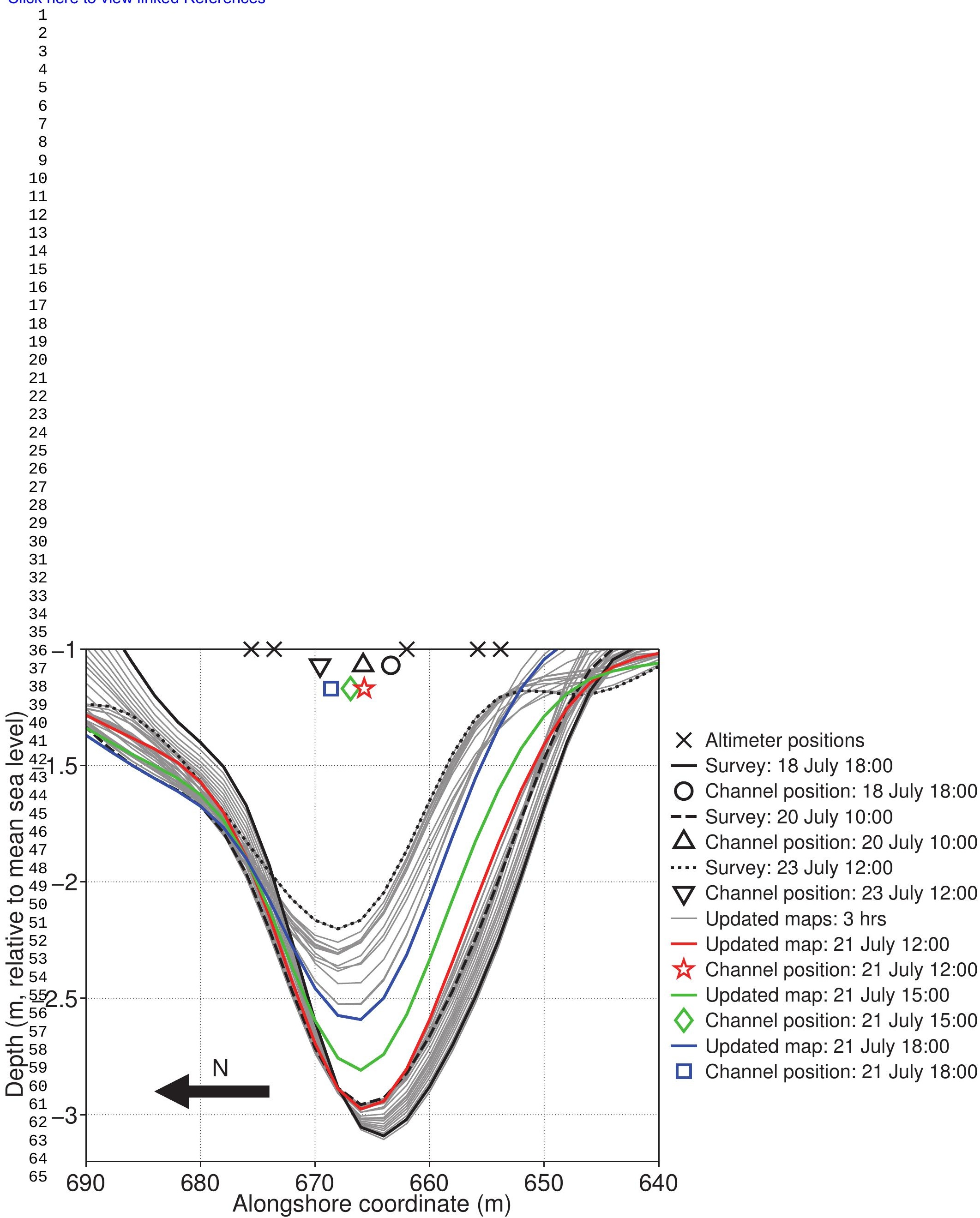




\section{Fig6}

Click here to download Manuscript: Fig6.eps

Click here to view linked References

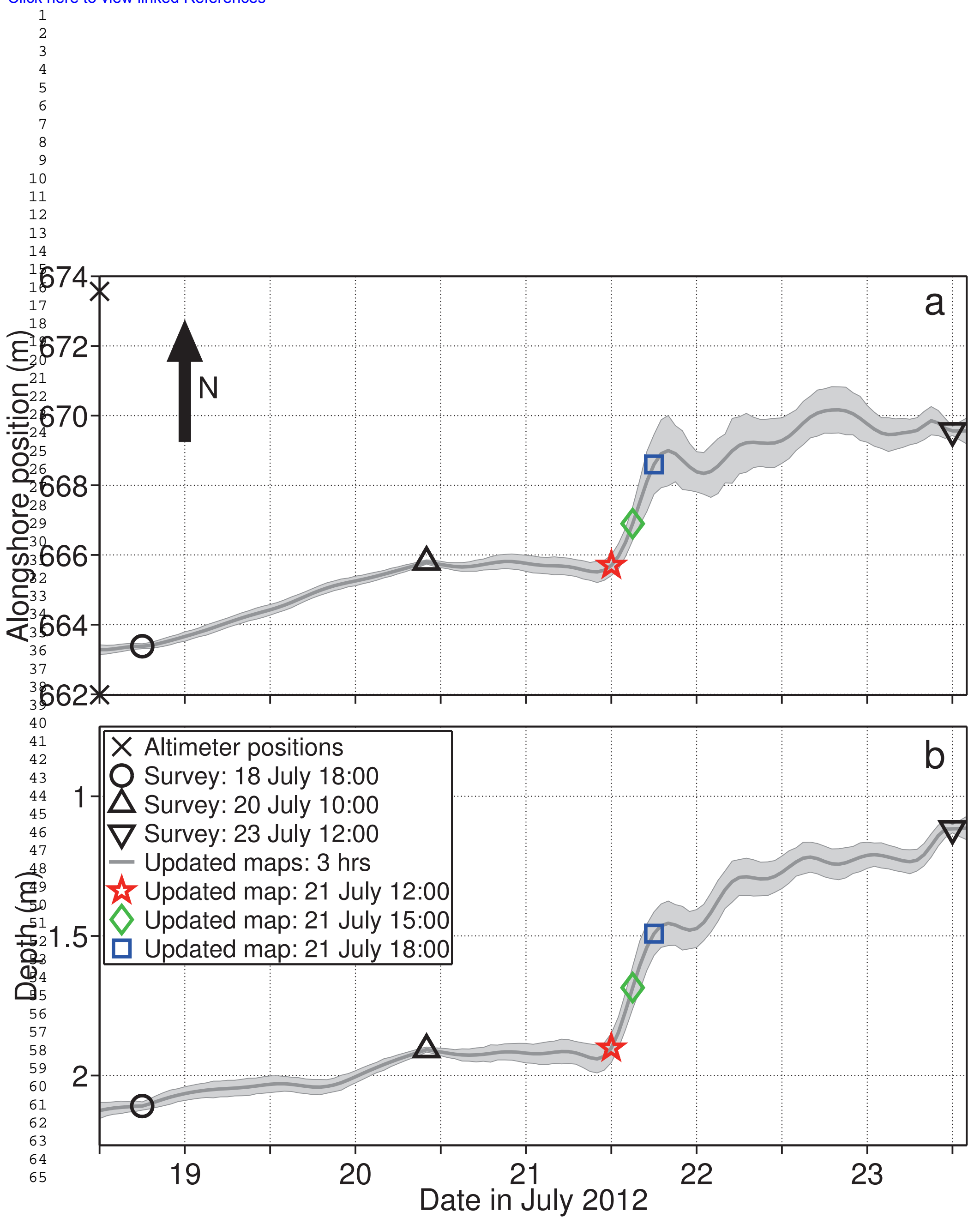

\section{Date in July 2012}




\section{Fig9}

Click here to download Manuscript: Fig9.eps

Click here to view linked References

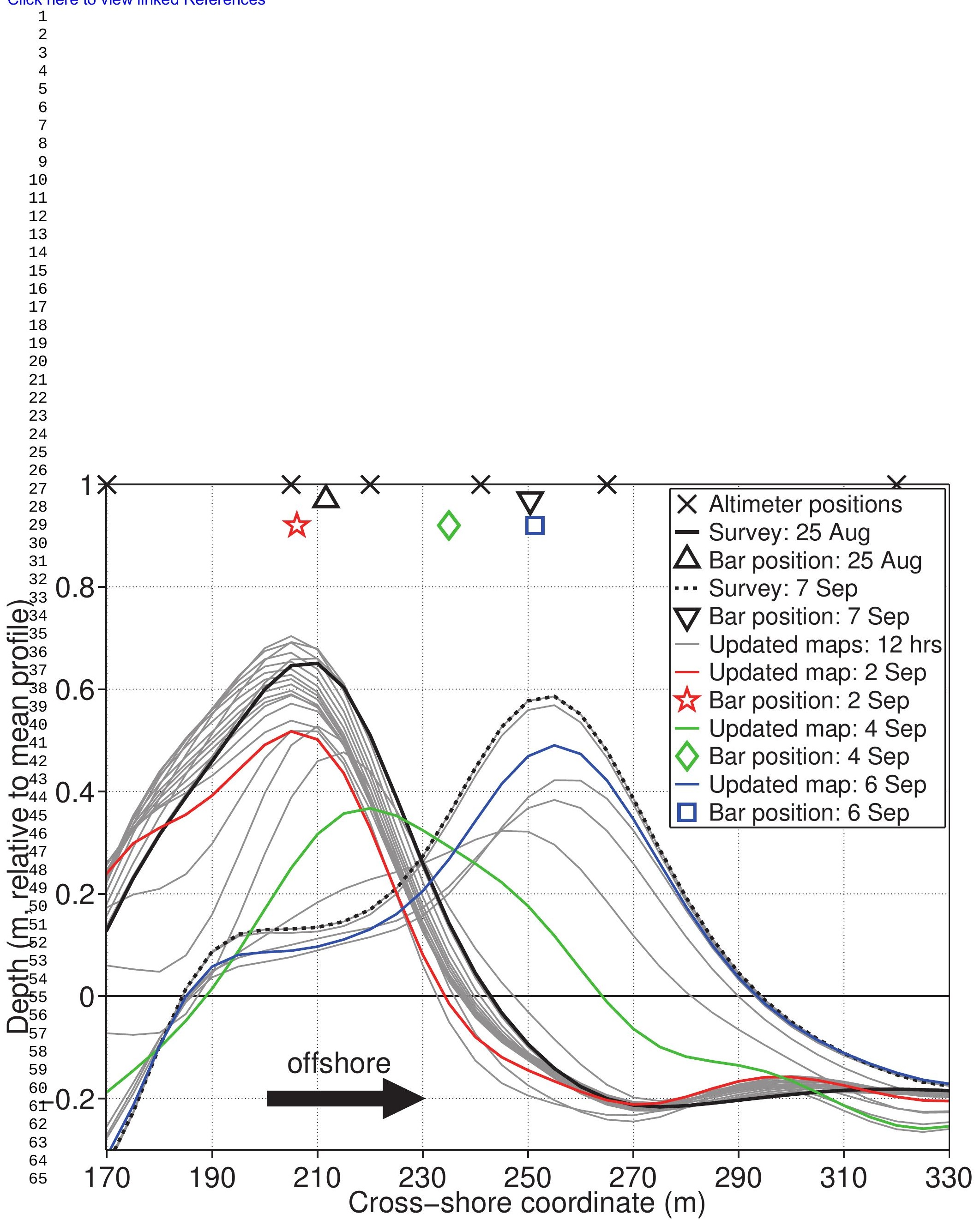




\section{Fig10}

Click here to download Manuscript: Fig10.eps

Click here to view linked References

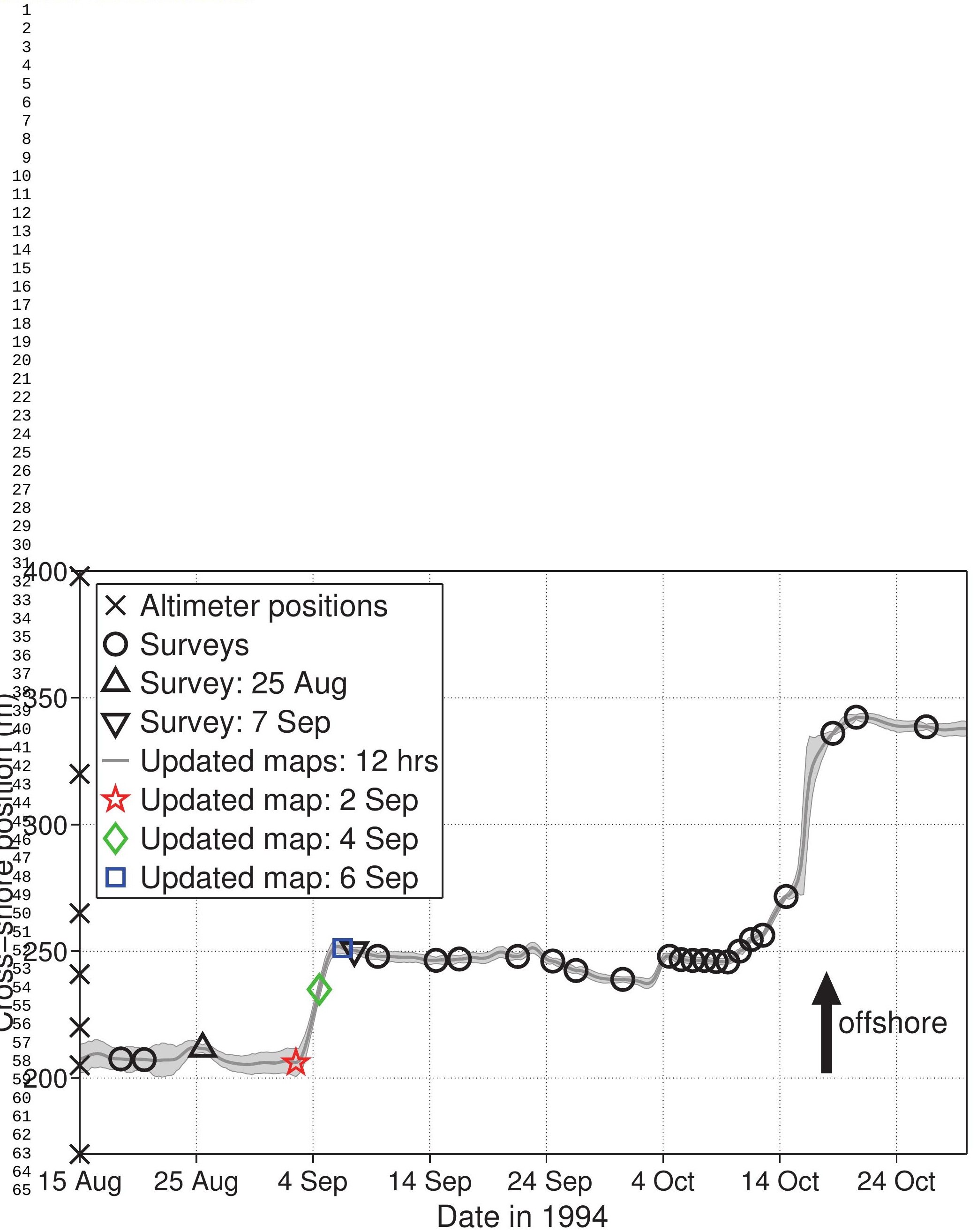

$\varepsilon_{4}^{3}$

$\digamma^{4}$

c

$\mathrm{O}^{4}$

$\mathbb{Q}_{4}^{4}$

c

$$
\text { o }
$$

d

${ }_{5}$

$$
\begin{aligned}
5 \\
5 \\
5
\end{aligned}
$$

1

2

$\times$ Altimeter positions

O Surveys

$\triangle$ Survey: 25 Aug

$\nabla$ Survey: 7 Sep

Updated maps. $12 \mathrm{hrs}$

« Updated map. 2 Sep

Updated map: 4 Sep

$\square$ Updated map: 6 Sep 